\title{
A Comparison Study of Patients Satisfaction Rate of Registry System in Two Referral Hospitals Emergency Settings
}

Aysa Rezabakhsh ( $\sim$ aysapharma.rezabakhsh@gmail.com )

Tabriz University of Medical Sciences

Orhan Delice

Erzurum Bolge Egitim ve Arastirma Hastanesi

Samad Shams Vahdati

Tabriz University of Medical Sciences

Senol Arslan

Erzurum Bolge Egitim ve Arastirma Hastanesi

\section{Hossein Hosseinifar}

Tabriz University of Medical Sciences

Alireza Ala

Tabriz University of Medical Sciences

Faride Houshmand

Tabriz University of Medical Sciences

Research article

Keywords: Patients Satisfaction, Registry System, Emergency Department, Quality of Health Care

Posted Date: December 13th, 2019

DOI: https://doi.org/10.21203/rs.2.18892/v1

License: (c) (1) This work is licensed under a Creative Commons Attribution 4.0 International License. Read Full License 


\section{Abstract}

\section{Background}

Patient satisfaction is an indirect indicator essential for evaluating the quality of care services and accurate predictor of health system policies. Recently, predictor factors affecting patient satisfaction are at the center of attention as well. The main objective of this study is to assess patient satisfaction rate during registry procedure in the emergency department of two referral hospitals.

\section{Methods}

An analytical cross-sectional study was conducted in both academic hospitals with high volume of patient admission in Tabriz-Iran and Erzurum-Turkey. We used a Press Ganey questionnaire as a data collection tool. Each patient or related companion filled out the self-administered questionnaire including 18 questions before discharging or referring to other area. Eventually, data were analyzed by using SPSS software version 16 .

\section{Results}

Overall, 462 respondents were enrolled in this survey during three part-time courses including morning shift (122 patients), evening shift (112 patients) and night shift (228 patients). $48.92 \%$ of participants were male and $51.08 \%$ were female. Our results demonstrated that total satisfaction score in new (model) registry system was two scores higher than classic one $(p<0.001)$. Furthermore, our findings showed a correlation between satisfaction rate and level of education and living place. In fact, patients with moderate education level in urban areas had higher satisfaction rate compared with rural regions (16 \pm 3.53 vs. $14.93 \pm 3.76 ; P=0.003)$ and higher/lower education levels $(16.3 \pm 3.35$ vs. $15.27 \pm 3.71$ and $15.67 \pm 3.86 ; p=0.03)$.

\section{Conclusion}

Take together attempts at improving patient flow as well as satisfaction rate in emergency department could reduce hospital costs and improve the quality of health care.

\section{Introduction}

Since the emergency department (ED) is represent the largest area of hospital admissions, overcrowding and subsequent delays in its throughput almost have important consequences and poorer outcomes during central triage such as uncertainty in ED, boarding of admitted patients, hospital longer stays, inaccessibility to appropriate hospital beds and lost opportunities to access on-time patients care services [1, 2]. Besides possible health effects, ED has a socio-economic impact following admission delays. Upon arrival to the emergency department, patients are first sorted by acuity in order to prioritize 
individuals requiring urgent medical intervention which called "triage" and routinely performed by one of expert hospital staff according to patient's chief compliant, demographic characteristics, and vital signs. Then, the patient should be visited by a medical provider who makes the initial care plan and finally recommends a disposition. Emergency medical management emerges as a professional discipline in the field of modern medicine and considered as an essential portion of primary care [3]. The initial identification of a medical emergency and subsequent management help medical system to save the patient's life, prevent irreversible outcomes and unintended consequences [4]. On the other hand, modification of registry system is interesting strategy for both admitted and discharged patients. Hitherto, there are different management strategies related to ED, such as long-term waiting caused by unreasonable factors, the unbalance operation of physicians and nurses and so on [5]. Additionally, registration is one of the critical management issues in the ED setting [6]. The Main purpose of registration process is patient reliable identification to ensure the information obtained following entering historical data in the Hospital Information System (HIS) for better diagnostic accuracy [7]. The second factor is thought to be timeliness which plays an important role in determining of patient satisfaction so that lengthy registration affects the patient safety and care and a large number of patients are frustrated by waiting long time in ED [8]. Additionally, the survey results showed a low satisfaction rate by patient companions after spending more time in registration queues [9]. Recently, He et al. designed an optimized registration process by using allocated resources based on system simulation for reducing waiting time in the emergency department of West China Hospital [5]. Another research also demonstrated that alternative admission policies by different physicians improved the registration system and reduced waiting times [10]. Up to the present time, there is little evidence in regard to patients satisfaction rate during registry procedure. Therefore, in this study we aimed to compare the satisfaction rate of central registry (classic) and local registry in each area (model) for timely triage to minimize delays in admission services and increase expected satisfaction rate. Regarding the lack of documented clinical research to evaluate different registry implementation in Iran, the results of this study could improve the quality of management issues in emergency medicine and other health care systems.

\section{Methods}

\section{Study design and patient population}

Tabriz and Erzurum are climatically and culturally similar. Nevertheless, the registry process in the ED settings is different. That's the reason we enrolled referral hospitals ED from Tabriz and Erzurum for a comparison study. An analytic cross-sectional study was conducted on 462 patients who referred to ED of Imam-Reza and Bölge tertiary hospitals in Tabriz-Iran and Erzurum-Turkey respectively with high patient volumes and approximately 400 to 600 daily visits. The survey research method was used to estimate the satisfaction rate of admitted subjects who randomly assigned by Excell software in different time courses (morning, evening, night) in the ED of both hospitals.

\section{Patient satisfaction related questionnaire}


This study will empirically collect patient questionnaire related to different areas (wards) of ED. By using a new registration system known as model registration at Erzurum hospital, we evaluated precisely demographic characteristics as well as time-related parameters and the efficiency of model registration. Then, the results were compared with the former registration system at Tabriz Imam-Reza hospital. The structured, pre-tested Press Ganey questionnaire was filled out by one of the hospital staff during a faceto-face interview. The subjects who were willing to participate in this study interrupted the interview only to clarify a question if required, but they did not reveal any information about the questions. The inclusion criteria included all randomized patients who referred to the ED and were triaged and the exclusion criteria consisted of all patients who quit the ED for any reason other than admission or discharge.

\section{Statistical analysis}

In this study, along with demographic characteristics, the satisfaction score of all patients and waiting times for classic and model registration systems were compared. Results were reported as a percentage and mean \pm standard deviation (SD) for qualitative and quantitative variables, respectively. Qualitative variables between two different systems were analyzed by Pearson Chi-square test. Univariate analysis was used to compare the mean of satisfaction score on the levels of independent variables by using independent t-test and Analysis of Variance (ANOVA). Linear regression models fitted data for evaluation of the factors affected satisfaction score. Those variables that had a p-value less than 0.2 in univariate analysis were entered into the regression model. Our data were analyzed by using SPSS software version 16 (SPSS Inc., Chicago, IL, USA). The p values less than 0.05 were considered as statistically significant.

\section{Results}

A total of 462 ED visits were participated in the current study, 199 (43.1\%) and 263 (56.9\%) patients were admitted through classic and model registry system, respectively. Demographic characteristics of all individuals during two different registry systems are fully explained in table 1 . As shown in figure 1, the mean age of the patients was $44.32 \pm 22.27$ (0-94 years old) in both methods. Based on our evaluation, the average satisfaction score increased significantly in model registry system compared to the classic system (16.41 \pm 3.23 vs. $14.66 \pm 3.9 ; p<0.001$; Figure 1$)$. The results of univariate analysis are shown in table 2. Based on Pearson's correlation coefficient, the relationship between satisfaction score and Age ( $\rho=-0.18)$, time for first visit $(\rho=-0.18)$, time for any area transferring $(\rho=-0.18)$, time for register $(\rho=-0.18)$ and time for decision ( $\rho=-0.18$ ) were statistically significant (Table $2 ; p<0.001)$. To assess the quality of model and classic registry systems, the analysis of different time courses of first visit, area transferring, time for registration and final decision was performed. Based on our findings, the requested time for first visit and area transferring were significantly prolonged in classic registry system (Table 3, $p<0.001$ ). Although the times of registration and final decision extended longer in model method, however the satisfaction score of model registry system was approximately two scores higher than classic method which directly refers to the quality of registration (Table $3, p<0.001$ ). Results of the multivariable logistic regression analysis to calculate the effect of independent variables on satisfaction score are presented in table 4. According to the results of regression modeling, some variables including methods of registry, 
first admission, time of first visit, time for register and time for final decision had significant effects on average changes of satisfaction score (Table4, $\mathrm{p}<0.001$ ). As shown in table 4 , the average satisfaction score in patients who admitted during the model registry, was higher (1.8 unit) than classic method $(\beta=1.80, p<0.001)$. Moreover, the average satisfaction score for patients who referred to ED for first time was 0.85 more than patients referred with more than once visit (Table 4, $\beta=0.85, p<0.001$ ). Linear regression modeling also determined that prolonged time for first visit, register and final decision, the satisfaction score decreased significantly. The results of satisfaction score of inter-group comparison for each method are shown in table 5 . Based on independent $t$-test analysis, the statistically significant differences were observed in classic and model methods related to some variables such as time of visit and who is completing (Table 5, $p<0.05$ ). However, admission shift for both methods was significantly different $(p<0.001)$. Interestingly, the highest satisfaction rate was observed in the morning shift (Table 5 , $p<0.001)$.

\section{Discussion}

Patient satisfaction is the extent to which patients are satisfied and pleased with their healthcare services. To assess health care quality, patient satisfaction gives new insights into the various aspects of medicine, such as the effectiveness of care services [11]. Satisfaction as an important factor when delivering any kind of in-hospital care service has recently gained notoriety in the medical centers. Regarding patient-centered health care reforms, patients are demanding a claim, and expect high-level healthcare and clarified services of their providers. ${ }^{12}$ Therefore, in order to optimize patient satisfaction assessment of health care quality is one of the imperative indicators that measured in a self-report study through a questionnaire [12]. Additionally, a fragmented and inefficient admission process may result in delays in the transition and impress patient flows of both admitted patients and other ED patients [13]. Our results supposed that ED registration procedure in each area could improve patient satisfaction rate and unmet needs in regards to health care services in comparison with central admission system. In line with our results, Soleimanpour et al. showed that the rate of general satisfaction was calculated about $34.9 \%$ in emergency medicine. ${ }^{11}$ However, no statistically significant differences were shown between gender and satisfaction rate while McKinley and et al demonstrated that satisfaction rate directly correlated with gender, age and social levels [14-15]. based on our findings a rational correlation was observed between satisfaction score and residence place in model registry system. In other words, satisfaction rate in most of the urban patients was significantly higher than rural areas. In this regards, some reasons can be mentioned for rural individuals such as lack of accessibility to facilities or accommodation problems $[17,18]$. It is worth noting that satisfaction rate in patients from urban regions with moderate level of education was higher than patients with higher/lower education levels. This could be related to more realistic point of view and rational level of expectation of them. Finally, it would be better to organize a throughput chart that consists of triage classification rules in each level, clear illustration of the necessity of patient's companion presence in where. This leads to increased patient's orientation and satisfaction rate as well as reasonable expectations during triage and registration process in ED. 


\section{Limitation}

Our study has some limitations. First, this study was conducted in two separated academic hospitals in different regions where the effects of admission policies were framed in the context of training mission and cannot be generalized to other hospitals. Therefore, the outcomes of the current study may be limited to academic health care settings. The second limitation concerns the sample size. We suggest future studies to increase the study sample size.

\section{Conclusion}

Providing high- quality care services required by patients who admitted in ED is one of the most important responsibilities. In this study, we aimed to compare two different registry procedures and evaluated satisfaction rate of admitted patients in regard to the enhancement of health care quality to reduce dissatisfaction as much as possible.

\section{Abbreviations}

ED: Emergency Department; HIS: Hospital Information System; SPSS: Statistical Package for the Social Sciences; ANOVA: Analysis of Variance; SD: Standard Deviation

\section{Declarations}

\section{Acknowledgements}

The authors would like to thank Dr. R. Rahbarghazi for his kind contribution in editing of the manuscript and the head of Bulge hospital and all staff who work across both sites (Imam Reza and Bulge hospitals).

\section{Authors' contributions}

OD and SSHV conceived the study and participated in design and coordination. SA collected the data. AR wrote the primary draft of the manuscript. AA developed the study design and contributed to manuscript preparation. HH performed the statistical analysis. All authors read and approved the final version of manuscript.

\section{Authors' information}

Not applicable

\section{Funding}

This research received no specific grant from any funding agency in public, commercial, or not-for-profit sectors. 
Availability of data and materials

All data generated or analyzed during this study are included in this published article.

\section{Ethical considerations}

The ethical approval which was attained from the local medical ethics committee of Tabriz University of Medical Sciences is IR.TBZMED.REC.1397.896. Additionally, informed consent was obtained from all individuals participated in this study.

\section{Consent for publication}

Participating in the simulation was deemed to constitute consent from the participants.

\section{Conflicts of interest}

The authors declare that they have no conflict of interest.

\section{References}

1. Asaro PV, Lewis LM, Boxerman SB. The impact of input and output factors on emergency department throughput. Academic Emergency Medicine. 2007; 14:235-42.

2. Bernstein SL, Aronsky D, Duseja R, Epstein S, Handel D, Hwang U, McCarthy M, John McConnell K, Pines JM, Rathlev N, Schafermeyer R, Zwemer F, Schull M, Asplin BR. The effect of emergency department crowding on clinically oriented outcomes. Academic Emergency Medicine. 2009; 16:1-10.

3. Gangaram P, Alinier G, Menacho AM. Crisis resource management in emergency medical settings in Qatar. International Paramedic Practice. 2017; 7:18-23.

4. Santos JLGd, Lima MADdS, Pestana AL, Regina E, Alacoque G, Erdmann L. Challenges for the management of emergency care from the perspective of nurses. Acta Paulista de Enfermagem. 2013; 26:136-43.

5. He Y, Cai B, Wang M. Research on Optimization of Registration Procedure in Emergency Department Based on System Simulation. Procedia Computer Science. 2016; 91:37-46.

6. Hakimzada AF, Green RA, Sayan OR, Zhang J, Patel VL. The nature and occurrence of registration errors in the emergency department. International journal of medical informatics. 2008; 77:169-75.

7. Tang PC, Ash JS, Bates DW, Overhage JM, Sands DZ. Personal health records: definitions, benefits, and strategies for overcoming barriers to adoption. Journal of the American Medical Informatics Association. 2006;13:121-6.

8. Al-Abri R, Al-Balushi A. Patient satisfaction survey as a tool towards quality improvement. Oman medical journal. 2014; 29:3.

9. Binsalih SA, Waness AO, Tamim HM, Harakati MS, Al Sayyari AA. Inpatients' care experience and satisfaction study. Journal of Family and Community Medicine. 2011;18:111. 
10. Kang H, Nembhard HB, Rafferty C, DeFlitch CJ. Patient flow in the emergency department: a classification and analysis of admission process policies. Annals of emergency medicine. 2014; 64:335-42. e8.

11. Soleimanpour H, Gholipouri C, Salarilak S, Raoufi P, Vahidi RG, Rouhi AJ, Ghafouri RR, Soleimanpour M. Emergency department patient satisfaction survey in Imam Reza hospital, Tabriz, Iran. International journal of emergency medicine. 2011; 4:2.

12. Tsai TC, Orav EJ, Jha AK. Patient satisfaction and quality of surgical care in US hospitals. Annals of surgery. 2015; 261:2.

13. Chartier L, Josephson T, Bates K, Kuipers M. improving emergency department flow through Rapid Medical Evaluation unit. BMJ Open Quality. 2015; 4:u206156. w2663.

14. Aragon SJ, Gesell SB. A patient satisfaction theory and its robustness across gender in emergency departments: a multigroup structural equation modeling investigation. American Journal of Medical Quality. 2003; 18:229-41.

15. Zohrevandi B, Tajik H. A survey of patients' satisfaction in emergency department of Rasht Poursina Hospital. Emergency. 2014; 2:162.

16. McKinley R, Stevenson K, Adams S, Manku-Scott T. Meeting patient expectations of care: the major determinant of satisfaction with out-of-hours primary medical care? Family practice. 2002; 19:333-8.

17. Soufi G, Belayachi J, Himmich S Ahid S, Soufi M, Zekraoui A, Abouqal R. Patient satisfaction in an acute medicine department in Morocco. BMC health services research. 2010; 10:149.

18. Reihani H, Pishbin E, Abbasi Shaye Z, Ebrahimi M, Bolvardi E, Talebi Delooi M, Momeni Moghaddam D, Vakili V. Patient satisfaction analysis in emergency department in Imam Reza hospital of Mashhad. Journal of Patient Safety \& Quality Improvement. 2015; 3:179-83.

\section{Tables}

Table 1. Demographic characteristics of all admitted patients. 


\begin{tabular}{|c|c|c|c|c|}
\hline & & \multicolumn{2}{|c|}{ Registration Method n (\%) } & \multirow[b]{2}{*}{ p-value ${ }^{*}$} \\
\hline & & Classic & New & \\
\hline Age (Mean \pm SD) & & $52.28 \pm 22.43$ & $38.25 \pm 20.16$ & $<0.001$ \\
\hline \multirow[t]{2}{*}{ Gender } & Male & $110(55.28 \%)$ & $121(46.01 \%)$ & 0.04 \\
\hline & Female & $89(44.72 \%)$ & $142(53.99 \%)$ & \\
\hline \multirow[t]{2}{*}{ First visit } & Yes & $96(48.24 \%)$ & $216(87.1 \%)$ & $<0.001$ \\
\hline & No & $103(51.76 \%)$ & $32(12.9 \%)$ & \\
\hline \multirow[t]{2}{*}{ Who is completing } & Patient & $25(12.56 \%)$ & $146(55.51 \%)$ & $<0.001$ \\
\hline & Patient Companion & $174(87.44 \%)$ & $117(44.49 \%)$ & \\
\hline \multirow[t]{2}{*}{ Residential place } & Urban Area & $89(44.95 \%)$ & $219(83.59 \%)$ & $<0.001$ \\
\hline & Rural Area & 109 (55.05\%) & $43(16.41 \%)$ & \\
\hline \multirow[t]{3}{*}{ Admission shift } & Morning & $77(38.69 \%)$ & $45(17.24 \%)$ & $<0.001$ \\
\hline & Evening & $45(22.61 \%)$ & $67(25.67 \%)$ & \\
\hline & Night & $77(38.69 \%)$ & $149(57.09 \%)$ & \\
\hline \multirow[t]{3}{*}{ Education } & Illiterate & $153(76.88 \%)$ & $122(49.39 \%)$ & $<0.001$ \\
\hline & Diploma & $32(16.08 \%)$ & $88(35.63 \%)$ & \\
\hline & Academic & $14(7.04 \%)$ & $37(14.98 \%)$ & \\
\hline
\end{tabular}

*p-value base Pearson Chi-square test

Table 2. Results of univariate analysis for comparison of satisfaction score in levels of in dependent variables. 


\begin{tabular}{|c|c|c|c|c|}
\hline & & $\mathbf{N}$ & Mean \pm SD & p-value* \\
\hline \multirow[t]{2}{*}{ Method } & Classic & 197 & $14.66 \pm 3.9$ & $<0.001$ \\
\hline & New & 259 & $16.41 \pm 3.23$ & \\
\hline \multirow[t]{2}{*}{ Who is completing } & Patient & 170 & $16.39 \pm 3.27$ & 0.001 \\
\hline & Another one & 286 & $15.22 \pm 3.78$ & \\
\hline \multirow[t]{3}{*}{ Admission shift } & Morning & 119 & $16.77 \pm 3.49$ & $<0.001$ \\
\hline & Evening & 112 & $16 \pm 3.55$ & \\
\hline & Night & 223 & $14.90 \pm 3.61$ & \\
\hline \multirow[t]{2}{*}{ First visit } & Yes & 308 & $15.59 \pm 3.57$ & 0.91 \\
\hline & No & 134 & $15.54 \pm 3.81$ & \\
\hline \multirow[t]{2}{*}{ Gender } & Male & 226 & $15.36 \pm 3.75$ & 0.08 \\
\hline & Female & 230 & $15.95 \pm 3.51$ & \\
\hline \multirow[t]{2}{*}{ Location } & Urban area & 303 & $16 \pm 3.53$ & 0.003 \\
\hline & Rural area & 151 & $14.93 \pm 3.76$ & \\
\hline \multirow[t]{3}{*}{ Education } & Illiterate & 271 & $15.27 \pm 3.71$ & $0.03^{* *}$ \\
\hline & Diploma & 119 & $16.3 \pm 3.35$ & \\
\hline & Academic & 51 & $15.67 \pm 3.86$ & \\
\hline
\end{tabular}

* base t-independent test $\quad * *$ base One-way ANOVA

Table 3. Comparison of different time courses for satisfaction score of registry procedure

\begin{tabular}{|l|l|l|l|l|}
\hline Method & N & Mean \pm SD & p-value \\
\hline \multirow{3}{*}{ Time for first visit } & Classic & 199 & $18.02 \pm 25.88$ & $<0.001$ \\
\cline { 2 - 4 } & Model & 263 & $7.55 \pm 8.81$ & \\
\hline Time for any area transfer & Classic & 199 & $7.13 \pm 8.85$ & $<0.001$ \\
\cline { 2 - 4 } & Model & 258 & $4.03 \pm 3.7$ & \\
\hline Time for register & Classic & 199 & $2.61 \pm 13.95$ & \multirow{2}{*}{0.028} \\
\cline { 2 - 4 } & Model & 263 & $4.9 \pm 5.14$ & \\
\hline Time for final decision & Classic & 199 & $31.82 \pm 51.31$ & $<0.001$ \\
\cline { 2 - 4 } & Model & 245 & $80.83 \pm 116.08$ & \\
\hline
\end{tabular}

Table 4. Predictors of patient's satisfaction 


\begin{tabular}{lllll}
\hline & & $\beta(S E)$ & t-value & P-value \\
\hline Registration Method & Classic & Ref & & \\
& Model & $1.8(0.43)$ & 4.210 & 0.000 \\
\cline { 2 - 5 } Who Is Completing & Patient & & & \\
& Patient Companion & $0.16(0.39)$ & 0.418 & 0.676 \\
\cline { 2 - 5 } First visit & Yes & Ref & & \\
& No & $-0.85(0.2)$ & -4.234 & 0.000 \\
\cline { 2 - 5 } Gender & Male & Ref & & \\
\multirow{3}{*}{$\begin{array}{l}\text { Residential place } \\
\text { Education }\end{array}$} & Female & $0.07(0.31)$ & 0.237 & 0.813 \\
\cline { 2 - 5 } & Urban Area & Ref & & \\
& Rural area & $0.05(0.37)$ & 0.128 & 0.898 \\
\cline { 2 - 5 } & Illiterate & Ref & & \\
Age & Diploma & $0.26(0.41)$ & 0.638 & 0.524 \\
Time For First Visit & Academic & $0.09(0.52)$ & 0.173 & 0.863 \\
Time For Any Area Transfer & & $-0.01(0.01)$ & -0.825 & 0.410 \\
Time For Register & & $-0.05(0.01)$ & -5.632 & 0.000 \\
Time For Decision & & $-0.05(0.02)$ & -1.882 & 0.061 \\
\hline & & $-0.06(0.02)$ & -3.889 & 0.000 \\
& & $-0.01(0.002)$ & -3.591 & 0.000 \\
\hline
\end{tabular}

Table 5. Comparison of Satisfaction Score regarding to independent variables in two registration systems 


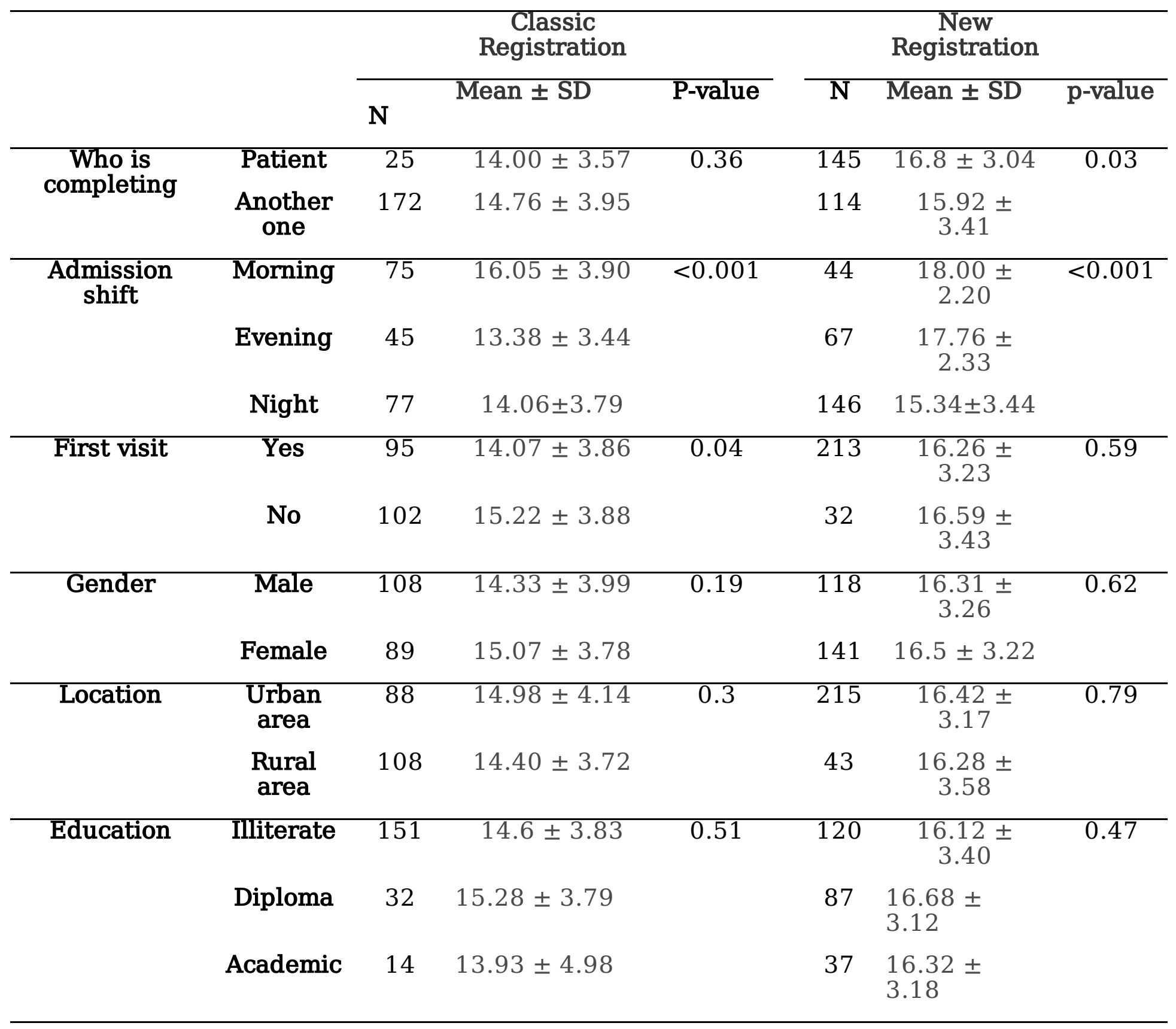

Figures 


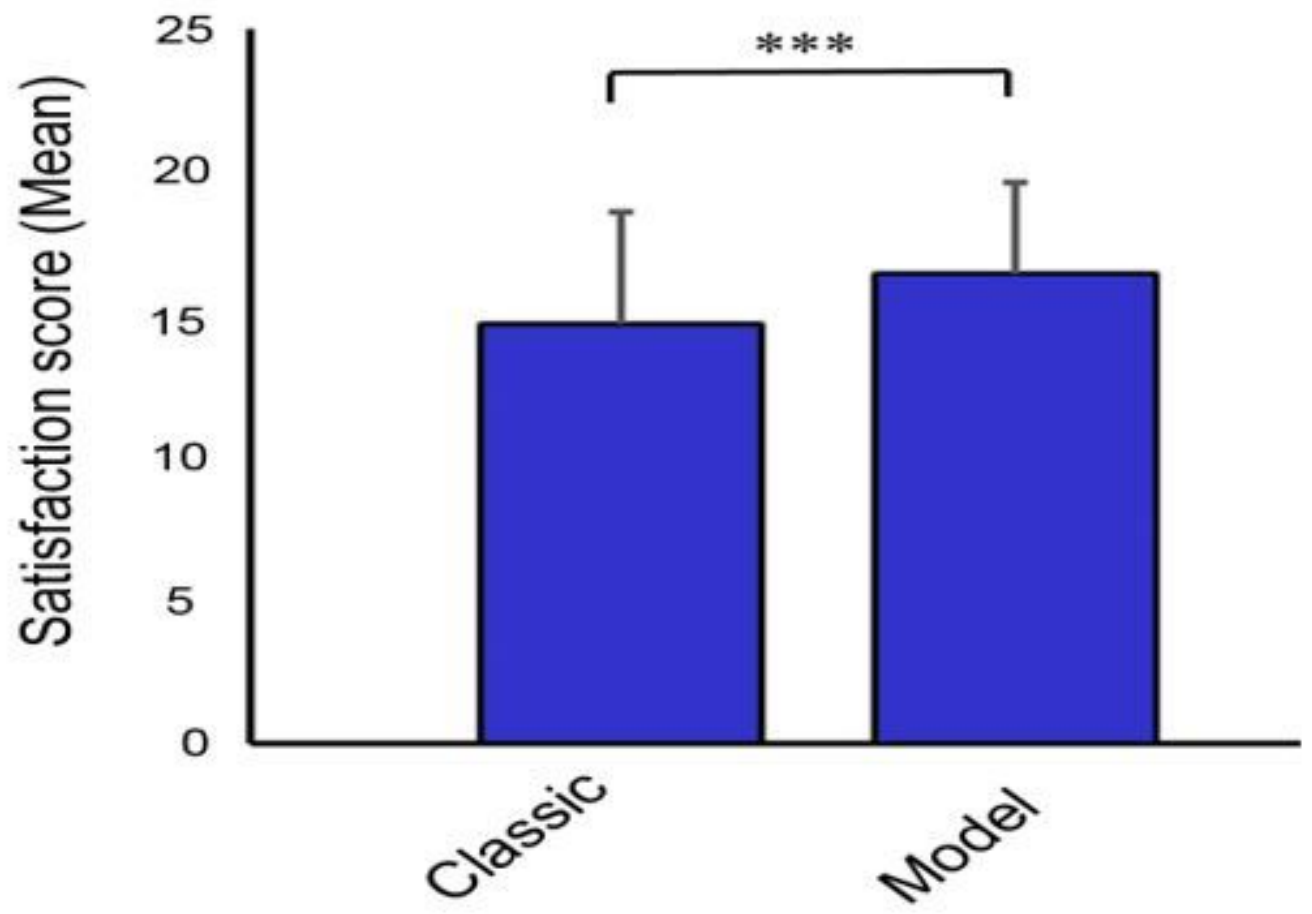

Figure 1

[No legend available.] 


\section{Classic registry procedure}

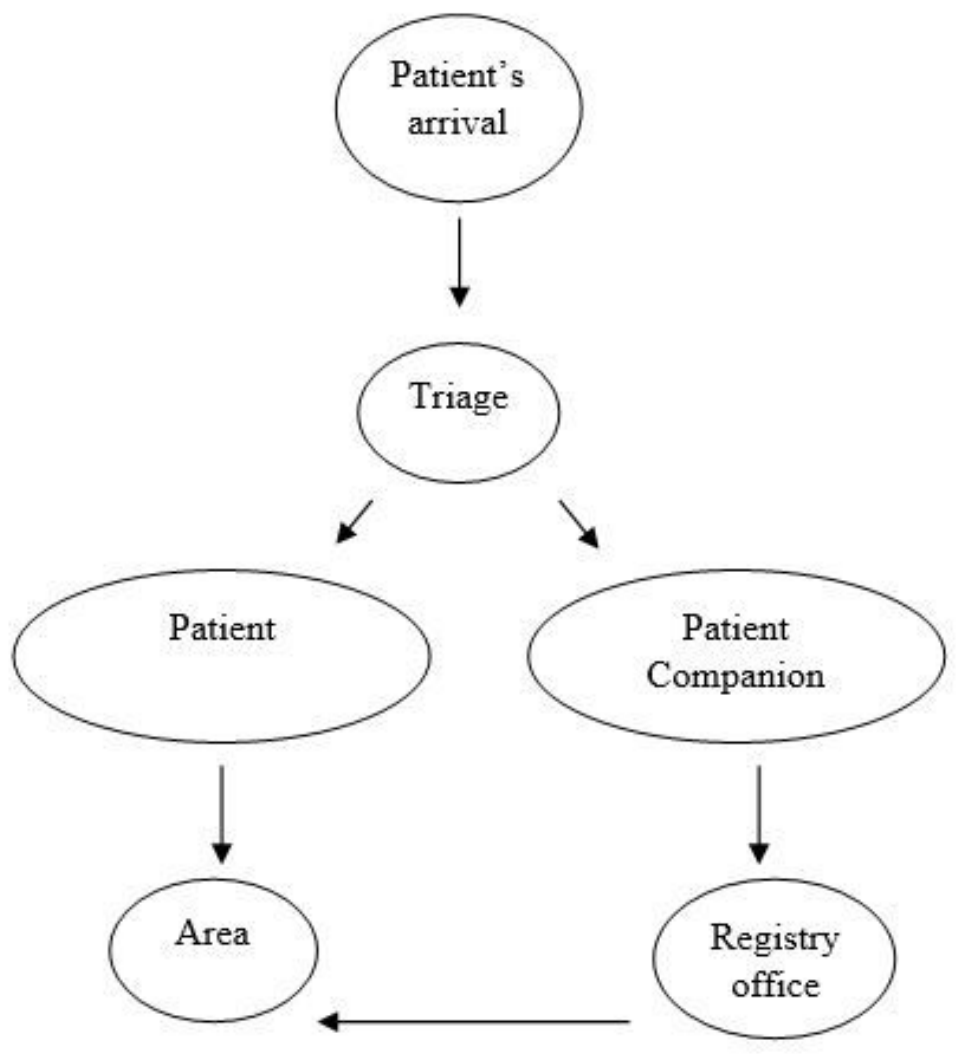

New registry procedure

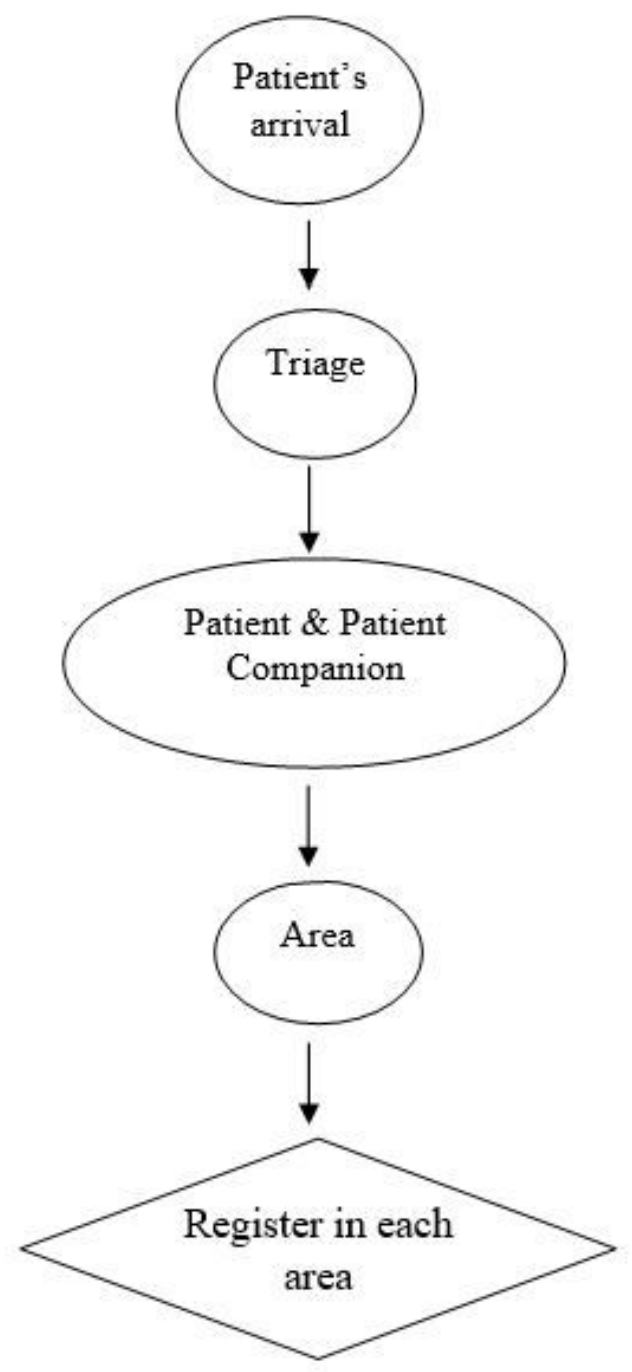

Figure 2

[No legend available.] 